\title{
Mate attraction, chemical defense, and competition avoidance in the parasitoid wasp Leptopilina pacifica
}

\author{
Lea C. Böttinger ${ }^{1}$ (D) . Frederic Hüftlein ${ }^{1}$ (D) . Johannes Stökl ${ }^{1}$ (D)
}

Received: 17 March 2020 / Accepted: 27 October 2020 / Published online: 12 November 2020

(c) The Author(s) 2020, corrected publication 2020

\begin{abstract}
A major hypothesis for the evolution of chemical signals is that pheromones arise from non-communicative precursor compounds. However, data supporting this hypothesis are rare, primarily because the original functions of the antecedent compounds often have been lost. A notable exception, however, is the parasitoid wasp species Leptopilina heterotoma, whose compound (-)-iridomyrmecin is used as a defensive secretion, a cue for females to avoid competition with con- and heterospecific females, and as the primary component of the females' sex pheromone. To better understand the evolution of sex pheromones from defensive compounds, we examined the chemical ecology of L. pacifica, the sister species of L. heterotoma. Here, we show that $L$. pacifica also produces a defensive secretion containing a species-specific mixture of mostly iridoid compounds. However, the composition of the secretion is more complex than in L. heterotoma, and iridomyrmecin is only a minor component. Moreover, in contrast to L. heterotoma, conspecific female competitors were not avoided by female subjects, and a role of the iridoids in the female sex pheromone of L. pacifica can be excluded, as only the females' cuticular hydrocarbons (CHCs) resulted in the elicitation of courtship by males. Although closely related, the two sister species show substantial differences in the use of the defensive secretion for communicative purposes. Variation in pheromone usage in this genus still presents a conundrum, highlighting the need for additional studies to understand the selective forces shaping the evolution of pheromone composition.
\end{abstract}

Keywords Figitidae $\cdot$ Pheromone $\cdot$ Evolution $\cdot$ Iridomyrmecin $\cdot$ Citral $\cdot$ Cuticular hydrocarbons

\section{Introduction}

Chemical communication is believed to be the oldest form of communication and is widespread in the animal kingdom (Wyatt 2014). However, the origin and evolution of chemical communication remains a major question in chemical ecology. Several thousand chemical compounds used in chemical communication have been identified

Communicated by Marko Rohlfs.

The original article has been revised: Due to textual changes.

Electronic supplementary material The online version of this article (https://doi.org/10.1007/s00049-020-00331-3) contains supplementary material, which is available to authorized users.

Lea C. Böttinger

Lea.Boettinger@uni-bayreuth.de

1 Institute of Evolutionary Animal Ecology, University of Bayreuth, Bayreuth, Germany
(El-Sayed 2020), and the diversity in chemical structures and relative amounts of substances allows an infinite number of complex odor compound combinations. The senderprecursor model posits that pheromone signals can arise via an evolutionary transition from precursor molecules that initially acted as chemical cues (Sorensen and Stacey 1999; Wyatt 2010; Bradbury and Vehrencamp 2011; Steiger et al. 2011; Stökl and Steiger 2017). Potentially, any chemical can evolve into a pheromone if it provides a selective advantage to both the sender and receiver (Wyatt 2014). A prerequisite for a compound to evolve into a pheromone is that it is produced and emitted by one individual in a non-communicative context and perceived by a second individual of the same species (Wyatt 2010). In this way, the compound acts as a chemical cue, transmitting information to the receiving individual without being selected for that function (Maynard Smith and Harper 2003). For example, a hormone released in urine, or alternatively, a defensive compound, can become a chemical cue. Selection can then act on the behavioral responses 
of the receiving individual, and ultimately ritualize and fine-tune the emission, sensitivity and specificity of the information transferred by this compound and its subsequent reception. Various fish pheromones have evolved via this mechanism, in which steroid hormones of females or their derivatives have been co-opted as sex pheromones over evolutionary time (Stacey and Sorensen 2011). If a pheromone compound is used for multiple functions, this is termed semiochemical parsimony and occurs in various species (Blum 1996; Bordereau and Pasteels 2011). Such parsimony corroborates the evolutionary transition that can ensue when the original function of a chemical compound is co-opted for its current use in pheromonal communication.

The iridoid compound (-)-iridomyrmecin functions as a defensive compound in the parasitic wasp Leptopilina heterotoma Тномрson 1862 (Hymenoptera, Figitidae) to deter predators (Stökl et al. 2012). Females of this species also use (-)-iridomyrmecin as a cue to avoid competition with conspecific and heterospecific females during host search and egg-laying (Weiss et al. 2013). Interestingly, (-)-iridomyrmecin also serves as the main component of the females' sex pheromone, which initiates mate finding, species recognition, and courtship (Weiss et al. 2013). Therefore, we can infer a functional shift from the use of (-)-iridomyrmecin as a defensive compound to its utility as a sex pheromone in female L. heterotoma. In L. heterotoma, (-)-iridomyrmecin is an example of a threefold chemical parsimony, extending our understanding of the evolutionary transition from a non-communicative defensive compound to a species-specific mating signal.

The diversity of the production and use of iridomyrmecins, as well as of sex pheromones, within the genus Leptopilina is highly diverse. All studied species of Leptopilina produce iridoid compounds, but with different stereoisomers of iridomyrmecin and several additional species-specific iridoid substances (Stökl et al. 2012; Weiss et al. 2013, 2015a; Pfeiffer et al. 2018; Böttinger et al. 2019). While the use of iridoids as defensive allomones and cues for competition avoidance appears to be common in the genus Leptopilina (Weiss et al. 2013; Pfeiffer et al. 2018; Böttinger et al. 2019, unpublished), their function as a sex pheromone has not evolved in all species (Fig. 1). Two species (Leptopilina heterotoma: Weiss et al. 2013; L. japonica: Böttinger et al. 2019) rely on iridoids as female sex pheromones, whereas all other species either use CHCs (L. victoriae: Weiss et al. 2015a; L. clavipes: Pfeiffer et al. 2018; L. ryukyuensis: Böttinger et al. 2019) or a combination of iridoids and CHCs $(L$. boulardi: Weiss et al. 2015a) in mate attraction and courtship initiation.

To date, nothing is known about the chemical communication of L. pacifica NovKović \& KIMURA 2011, the sister species of L. heterotoma (Novković et al. 2011; Wachi et al. 2015). Whereas L. heterotoma occurs in the Holarctic as well as in the Oriental region (Allemand et al. 2002) and parasitizes various drosophilid flies (Carton et al. 1986), $L$.
Fig. 1 Phylogenetic relationship and current knowledge on the production and use of iridoids by the nine species of Leptopilina studied so far. $(+)$ indicates that $(+)$-iridomyrmecin is produced (among other iridoid compounds), and $(-)$, that (-)-iridomyrmecin is produced. Hyphens indicate that this function has not been studied. In bold is the here studied species and the results presented in this study. Phylogenetic tree based on ITS2, modified from Wachi et al. (2015). ${ }^{1}$ Weiss et al. (2015a), ${ }^{2}$ Böttinger et al. (2019), ${ }^{3}$ Stökl et al. (2012), ${ }^{4}$ Pfeiffer et al. (2018), here, the defensive function of iridoids is assumed, but has not been experimentally tested; ${ }^{5}$ Weiss et al. (2013); ${ }^{6} \mathrm{Böttinger}$ and Stökl (2020), ${ }^{7}$ unpublished

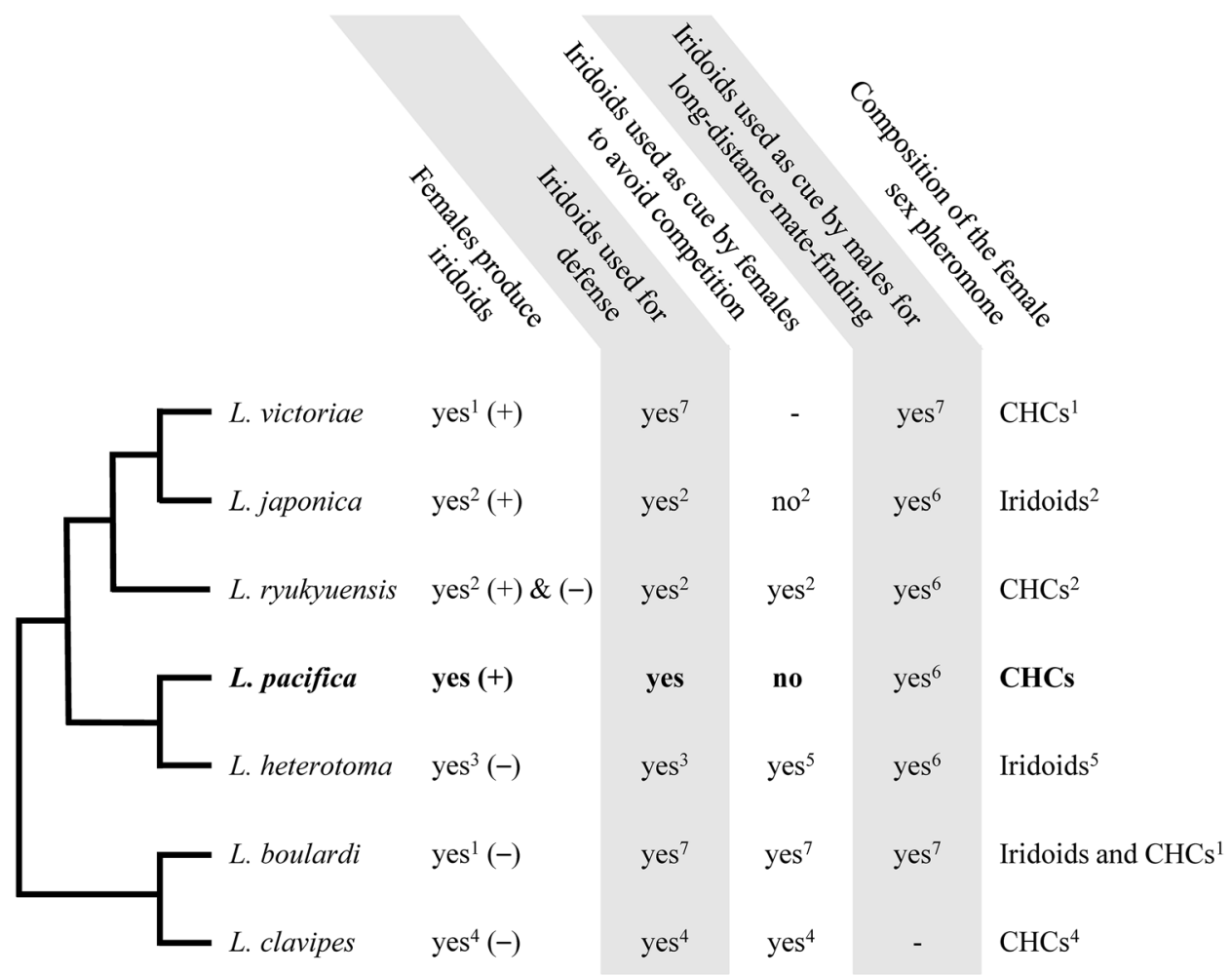


pacifica is an oriental species occurring in subtropical and tropical regions of Asia (Novković et al. 2011) and develops on hosts of the D. immigrans group (Kimura and Suwito 2012). In this study, we ask: Does L. pacifica, as previously documented in $L$. heterotoma, (1) produce iridoid compounds, (2) emit these for defensive purposes, (3) use these as cues for females to avoid competition, and (4) as female sex pheromone signal for males to find females?

To address this question, we analyzed the production and use of chemical compounds in L. pacifica. We report on the compounds released as defensive secretions upon attack or disturbance of $L$. pacifica, and on the competition avoidance behavior of female wasps during host finding. We identify the components of the sex pheromone of female $L$. pacifica wasps by analyzing the courtship behavior exhibited by males in response to specific female compounds. For the evaluation of courtship behavior, the duration of male wingfanning display is used, which Leptopilina males display upon perception of conspecific females and maintain during all stages of courtship. Elucidating the communication system of L. pacifica, specifically, their reliance on iridoids, should yield important insights into the evolutionary trajectories promoting variation in sexual signaling within the genus Leptopilina.

\section{Material and methods}

\section{Experimental animals}

A strain of the parasitoid wasp Leptopilina pacifica was collected by M. T. Kimura in June, 2011 on Irimote-jima, Japan and maintained in the laboratory using Drosophila virilis STURTEVANT as a host species. For each rearing bout, about 30 $D$. virilis flies of both sexes were placed into a jar containing fresh corn-based Drosophila medium (1 1 water, $50 \mathrm{~g}$ cornmeal, $50 \mathrm{~g}$ wheat germ, $50 \mathrm{~g}$ sugar, $40 \mathrm{~g}$ baker's yeast, $8 \mathrm{~g}$ agar, $5 \mathrm{ml}$ propionic acid). Four days later, when the flies had laid eggs, the flies were removed and approximately 15 female and male L. pacifica wasps were introduced into the jar. Drosophila virilis flies and L. pacifica wasps were kept in a climate and light controlled environment at $24^{\circ} \mathrm{C}$, $60 \%$ humidity and a 16:8 h L:D cycle. A few days before wasp emergence (approximately three weeks after oviposition), the parasitized fly pupae were singly isolated from the jars in $1.5 \mathrm{ml}$ microcentrifuge tubes and provided with diluted honey ad libitum. This protocol allowed us to obtain unmated and naïve wasps of known age and sex. Mated females were obtained by placing a single 1-day-old female together with a male wasp for $12 \mathrm{~h}$ in a microcentrifuge tube. Subsequently, the wasps were again isolated and fed with diluted honey ad libitum. Each individual wasp was only used once in an experiment.

To rear predators of $L$. pacifica for the analysis of defensive compounds emitted by wasps, larvae of the Common Green Lacewing Chrysoperla carnea STEPHENs (Neuroptera: Chrysopidae) (obtained from Katz Biotech AG, Baruth, Germany) were maintained individually in 48-well plates to avoid cannibalism. They were kept in a climate and light controlled environment at $24{ }^{\circ} \mathrm{C}, 60 \%$ humidity and a $16: 8 \mathrm{~h}$ L:D cycle, and fed ad libitum with Sitotroga cerealella OLIVIER eggs. Each $C$. carnea larva was used only once in an experiment.

\section{Chemical analyses}

For qualitative chemical analyses and behavioral experiments, extracts of males and females of L. pacifica were obtained by extracting each sex in batches of 30 to 100 individuals for $10 \mathrm{~min}$ in $10 \mu \mathrm{l}$ dichloromethane (DCM) per individual. These pooled extracts were analyzed with an Agilent 7890 gas chromatograph (GC; Agilent Technologies, Germany), equipped with a non-polar capillary column (DB-5, $30 \mathrm{~m}, 0.25 \mathrm{~mm}$ i.d., $0.25 \mu \mathrm{m}$ film thickness; Agilent Technologies, Germany) and coupled to an Agilent 5977A mass spectrometer (MS; Agilent Technologies, Germany). The injector temperature was set to $280^{\circ} \mathrm{C}$ and samples were injected splitless. Helium was used as the carrier gas at a constant linear velocity of $50 \mathrm{~cm} \mathrm{~s}^{-1}$. The GC oven was heated from $80{ }^{\circ} \mathrm{C}$ with $5{ }^{\circ} \mathrm{C} \mathrm{min}-1$ to $280{ }^{\circ} \mathrm{C}$, where the temperature was held for $20 \mathrm{~min}$. The MS was operated in electron impact (EI) mode at $70 \mathrm{eV}$ and scanned a massrange between 30 and $500 \mathrm{mz}^{-1}$.

Compounds in extracts were identified by comparing their mass spectra, diagnostic ions, and Kovats retention indices to those of synthetic reference compounds and known compounds from other species in the genus. To identify and separate the iridoid compounds enantioselectively, additional analyses were performed on a chiral capillary column (CycloSil-B, $30 \mathrm{~m}, 0.25 \mathrm{~mm}$ i.d., $0.25 \mu \mathrm{m}$ film thickness; Agilent Technologies, Germany), in which injector temperature was set to $250^{\circ} \mathrm{C}$ and the oven temperature was held at $80{ }^{\circ} \mathrm{C}$ for $4 \mathrm{~min}$, before it was raised at $3^{\circ} \mathrm{min}^{-1}$ to $230{ }^{\circ} \mathrm{C}$. Methyl-branched alkanes were identified by comparing their retention indices with data from the literature (Carlson et al. 1998) and interpretation of diagnostic ions (Nelson 1993). Double-bond positions of mono- and di-unsaturated compounds were determined by derivatizing samples with dimethyl disulfide (Carlson et al. 1989). Derivatized samples were then analyzed on a Shimadzu GC2030 coupled to a QP2020NX MS equipped with a SH-Rxi-5 ms column (30 m, $0.25 \mathrm{~mm}$ i.d., $0.25 \mu \mathrm{m}$ film thickness). The other parameters were set as in the previous analysis, but the final 
oven temperature was increased to $310{ }^{\circ} \mathrm{C}$ and the massrange increased to $800 \mathrm{mz}^{-1}$.

For quantification of compounds produced by male and female $L$. pacifica, 15 wasps of each sex were extracted individually for $10 \mathrm{~min}$ in $20 \mu \mathrm{l}$ of DCM with $20 \mathrm{ng} \mu \mathrm{l}^{-1}$ methyl undecanoate as internal standard. These samples were analyzed on the Agilent GC/MS system as described above and the amounts of compounds determined by comparing their integrated peak areas with those of the respective internal standard. For the calculation of absolute amounts of volatile compounds, external standard calibration curves were obtained by analyzing different concentrations of synthetic (+)-iridomyrmecin $\left(2,5,10,20,50 \mathrm{ng}^{-1} \mathrm{l}^{-1}\right)$ together with the internal standard. For the absolute quantification of $\mathrm{CHCs}$, external calibration curves with known amounts of 9-tricosene and tricosane, always 1, 5, 10, 25, $50 \mathrm{ng} \mathrm{\mu l}^{-1}$, together with the internal standard, were conducted.

\section{Fractionation of extracts}

To identify the behaviorally active compounds, the females' extracts were separated into volatile polar compounds and non-polar CHC compounds by solid-phase extraction. Samples were dried under a gentle stream of nitrogen, re-dissolved in $50 \mu \mathrm{l}$ of hexane, and applied on a cyanopropyl-modified silica gel column $(50 \mathrm{mg}$, DSC-CN, Sigma-Aldrich, Taufkirchen, Germany), which had been pre-conditioned by rinsing with $2 \mathrm{ml}$ of DCM and hexane. The non-polar CHC compounds of the samples were eluted from the column with $150 \mu \mathrm{l}$ hexane, and subsequently the column was flushed with $500 \mu \mathrm{l}$ of hexane. Then, the polar iridoid substances of the sample were eluted with $150 \mu \mathrm{l}$ DCM. The fractions were analyzed by GC/MS as described above and their concentration re-adjusted to the concentration of the original extract.

\section{Iridoids for defense}

We analyzed the volatile organic compounds released from $L$. pacifica wasps when attacked by natural enemies to determine whether L. pacifica wasps emit iridoid compounds as deterrent allomones. To that end, two female wasps of $L$. pacifica were carefully placed in a $1 \mathrm{ml}$ glass vial together with a previously starved third instar larva of the Common Green Lacewing (Chrysoperla carnea), after the wasps were left there for $30 \mathrm{~s}$ to acclimate. The amounts of compounds emitted by the female $L$. pacifica wasps were measured using dynamic headspace collection. For this, a headspace needle trap device (packed with $3 \mathrm{~cm}$ Tenax TA, NeedlEx, Shinwa Chemical Industries LTD, Japan) was inserted into the vial containing the wasps and the lacewing larvae. Air was drawn through the needle for $5 \mathrm{~min}$ at a rate of $6 \mathrm{ml} \mathrm{min}^{-1}$ by a sampling system (PAS Technology, Germany). An activated charcoal filter (50 mg, ORBO, Sigma-Aldrich) cleaned the air flowing into the vial. Volatiles emitted by the $L$. pacifica females were adsorbed in the needle, which was subsequently thermally desorbed in the hot injector of the Agilent GC/MS system and analyzed with the same settings as described above. As a control, two female wasps without a lacewing larva were put in the vial and their emitted compounds were collected and analyzed. Experiments were conducted 15 times per treatment (attack vs. control), and after each experiment, a new vial as well as new wasps and lacewing larvae were used. The activity of the lacewing larvae varied greatly between experiments, and so too did the amount of volatiles released by the wasps. Therefore, a second experiment with a standardized simulation of predatory attacks was performed in which the lacewing larvae were replaced with a small magnetic stir bar $(8 \times 3 \mathrm{~mm})$. The stir bar was moved for $2 \mathrm{~s}$ every $30 \mathrm{~s}$ with a magnet from outside the vial to simulate an attack on the wasps. Chemicals were trapped and analyzed as in the previous experiment. Experiments were conducted 15 times per treatment (teasing vs. control), and after each experiment, the magnetic stir bar was washed twice with DCM and a new vial and new wasps were used. For the calculation of absolute amounts of volatile compounds, an external standard calibration curve was obtained by analyzing different concentrations of synthetic (+)-iridomyrmecin $\left(1,5,10,25,50 \mathrm{ng}^{-1}\right)$.

\section{Female competition avoidance}

The avoidance behavior of females towards conspecifics during host search was investigated using a Y-tube olfactometer. The glass Y-tube was positioned at a $30^{\circ}$ slope with the arms pointed upwards and illuminated by two LED-tubes (white light, $350 \mathrm{~lm}, 5 \mathrm{~W}$ ) from above. The inner diameter of the Y-tube was $1.5 \mathrm{~cm}$, the base had a length of $6 \mathrm{~cm}$, and the arms had a length of $9 \mathrm{~cm}$ and were spread at a $45^{\circ}$ angle. Both ends of the arms were connected via Teflon tubes to separate Erlenmeyer flasks $(50 \mathrm{ml})$, which contained host patches ( $\sim \mathrm{g}$ of corn-based diet containing fresh $D$. virilis larvae). Humidified air was pumped through the flasks into

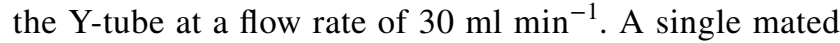
female wasp was carefully placed at the entrance of the base of the Y-tube and could decide between the two odor cues. The experimental test was stopped after $10 \mathrm{~min}$ (no choice) or once the female had crossed a decision line $2 \mathrm{~cm}$ beyond the branching point in each arm. After each test, the sample and control odor arm were alternated by turning the Y-tube. After every second test, the Y-tube was rinsed with ethanol and hot water and left to dry. To increase the number of responsive females, mated females were allowed to lay eggs in groups of 10-20 females on a host patch prior to the experiment. Each experiment was replicated until 30 females had crossed one of the decision lines. In the first experiment, 
the females had to choose between the odor of a host patch with 20 live mated $L$. pacifica females and the odor of a host patch without wasps. In the second experiment, the females had to choose between the odor of a host patch with $2 \mu \mathrm{l}$ of extract of females and the odor of a host patch with the solvent. Extract and solvent were applied to small discs of filter paper ( $5 \mathrm{~mm}$ diameter) and left to dry until the solvent evaporated. The paper discs were then placed directly into the arms of the Y-tube.

\section{Female sex pheromone}

Males of $L$. pacifica show wing fanning behavior, a high-frequency vibration of the wings, when they perceive and court a conspecific female. During all stages of the male courtship (perception, attraction, recognition, and approaching of the female, touching the females' antennae, mounting, antennal stroking, and, upon acceptance, copulation), wing fanning is maintained (Jenni 1951; van den Assem 1968; Isidoro et al. 1999). The duration of wing fanning indicates how much the male assumes that a female is nearby. We, therefore, used the duration of the wing fanning to measure the attractiveness of the females' compounds. Extracts of females $(2 \mu \mathrm{l})$, fractions thereof (always representing 1/5th equivalent of a female), or a solvent control were applied to a small discs of filter paper ( $5 \mathrm{~mm}$ diameter), left for $30 \mathrm{~s}$ to let the solvent evaporate, and then placed in a glass arena $(15 \mathrm{~mm}$ diameter, $4 \mathrm{~mm}$ height). Male wasps emerge 1-2 days before conspecific females (Böttinger and Stökl 2020), are directly sexually mature, and mating then takes place shortly after female emergence (pers. observation). Therefore, naïve 2-5-day-old males were used in this experiment. A single male wasp was introduced to the arena and its behavior recorded with a camera (Canon 70D, $100 \mathrm{~mm}$ macro objective) for $180 \mathrm{~s}$. The total duration of the male's wing fanning behavior within these $180 \mathrm{~s}$ was analyzed using the video analysis software BORIS (Friard and Gamba 2016). Each extract, fraction and control were tested 20 times using a new male for each experiment. Impregnated filter papers and each male were only used once. After each replicate, the arena was rinsed with ethanol and hot water and left to dry at room temperature.

\section{Statistics}

Emitted amounts of volatile compounds of female wasps were compared between treatment groups (attacked vs. control; teased vs. control) using Mann-Whitney $U$ tests. Decisions of female wasps in the Y-tube-experiments were analyzed with two-sided binomial tests. Differences in total wing fanning durations of males towards extracts, fractions, or the control were analyzed with a non-parametric Kruskal-Wallis ANOVA, followed by post hoc pairwise comparisons using Mann-Whitney $U$ tests with BonferroniHolm correction (Benjamini and Hochberg 1995). All statistical analyses were performed using $\mathrm{R}$ version 3.3.0 ( $\mathrm{R}$ Core Team 2017).

\section{Results}

\section{Chemical analyses}

In extracts of female and male wasps of L. pacifica, we identified compounds from mainly two substance classes, iridoids and CHCs. Additionally, we found (Z)-3,7-dimethyl2,6-octadienal (neral) and (E)-3,7-dimethyl-2,6-octadienal (geranial). Our chemical analyses furthermore revealed clear sex-specific qualitative and quantitative differences in the chemical profiles of female and male L. pacifica wasps. Females produce 20 volatile compounds (iridoids and citral), with iridodial, actinidine and nepetalactone being among the most abundant. In males, which produce only 11 volatile compounds, citral, actinidine and nepetalactone 2 dominate the profile of volatile compounds. Quantitatively, the volatile compounds (iridoids, neral, geranial) made up $392.36 \pm 206.47 \mathrm{ng}$ (mean $\pm \mathrm{SD}$ ) or $45.05 \%$ of all compounds in females. In contrast, extracts of males contained on average only about $99.52 \pm 40.17 \mathrm{ng}($ mean $\pm \mathrm{SD})$ volatile compounds ( $16.38 \%$ of total compounds), from which $48.57 \%$ were neral and geranial. Female L. pacifica thus produce not only a more complex iridoid blend than males, their extracts also contained substantially higher quantities of iridoids (Table 1, Fig. 2).

The CHC composition found in extracts of male and female $L$. pacifica was qualitatively similar, but females had more compounds and greater quantities of $\mathrm{CHCs}$ than males. The wasps' CHC profiles contained mainly mono- and diunsaturated alkanes or methyl branched alkanes. Although the CHCs were dominated by 4-methyl triacontane, 9-hentriacontene, and 4-methyl dotriacontane in both sexes, males additionally produced high amounts of 9,19-pentatriacontadiene. In total, we identified $31 \mathrm{CHC}$ compounds in the extracts of female and male wasps (Table 1).

\section{Iridoids for defense}

In these experiments, we tested whether females of $L$. pacifica emit iridoids as deterrents to defend themselves against natural predators. In the first experiment, we let single $3^{\text {rd }}$ instar larvae of $C$. carnea attack two females of $L$. pacifica and analyzed the emitted compounds during these 5 min encounters. Females released not only iridoids, but also citral (the mixture of neral and geranial) as deterrents. Females released on average $1.78 \pm 3.17 \mathrm{ng}$ (mean $\pm \mathrm{SD}$ ) of citral and iridoids in a non-defensive 
Table 1 Quantitative Analysis of compounds produced by male and female Leptopilina pacifica wasps

\begin{tabular}{|c|c|c|c|c|c|c|}
\hline No & Compound & KRI & Diagn. Ions & Diagn. Ions DMDS & $\begin{array}{l}\text { Mean amount } \\
(\mathrm{ng} \pm \mathrm{SD}) \text { per } \\
\text { female }\end{array}$ & $\begin{array}{l}\text { Mean amount } \\
(\mathrm{ng} \pm \mathrm{SD}) \text { per } \\
\text { male }\end{array}$ \\
\hline 1 & $\begin{array}{l}\text { (Z)-3,7-dimethyl-2,6-octadie- } \\
\text { nal (neral) }\end{array}$ & 1247 & $69,84,94 / 5,109$ & & $14.21 \pm 7.48$ & $17.81 \pm 6.25$ \\
\hline 2 & Unknown compound & 1258 & $69,84,94,109,122 / 3$ & & $4.54 \pm 3.18$ & - \\
\hline 3 & Unknown compound & 1265 & $69,95,109,122 / 3$ & & $1.60 \pm 0.94$ & - \\
\hline 4 & $\begin{array}{l}\text { (E)-3,7-dimethyl-2,6-octadie- } \\
\text { nal (geranial) }\end{array}$ & 1276 & $69,84,94,109,123,137,152$ & & $21.98 \pm 11.47$ & $30.52 \pm 11.01$ \\
\hline 5 & Iridodial & 1293 & $67,84,86,111,135$ & & $0.97 \pm 0.54$ & - \\
\hline 6 & Iridodial 1 & 1303 & $67,81,109,111,135$ & & $71.07 \pm 52.26$ & $0.91 \pm 0.68$ \\
\hline 7 & Iridodial 2 & 1306 & $67,81,109,111,135$ & & $34.06 \pm 18.29$ & $1.69 \pm 1.51$ \\
\hline 8 & Unidentified iridoid & 1326 & $69,83 / 84,97 / 98,135$ & & $5.52 \pm 2.54$ & $1.75 \pm 0.48$ \\
\hline 9 & Unidentified iridoid & 1333 & $69,81,84,107,109,111,135$ & & $0.79 \pm 1.26$ & - \\
\hline 10 & $\begin{array}{l}\text { Actinidine; in females coelut- } \\
\text { ing with unidentified puta- } \\
\text { tive iridoid }\end{array}$ & 1341 & $\begin{array}{l}117,132,147 ; 69,95,108 / 9 \\
137\end{array}$ & & $69.20 \pm 43.36$ & $10.26 \pm 8.72$ \\
\hline 11 & Unknown putative iridoid ${ }^{\mathrm{a}}$ & 1349 & $69,83,93,108,137$ & & $51.32 \pm 36.92$ & - \\
\hline 12 & Nepetalactone $1^{\mathrm{b}}$ & 1363 & $81,95,109,123,166$ & & $5.25 \pm 3.01$ & - \\
\hline 13 & Nepetalactone $2^{\mathrm{b}}$ & 1372 & $69,81,95,109,123,166$ & & $66.56 \pm 32.78$ & $27.48 \pm 11.71$ \\
\hline 14 & Unknown compound & 1381 & $67,81,84,111,135$ & & $1.63 \pm 1.05$ & - \\
\hline 15 & Unknown compound ${ }^{c, d}$ & 1391 & $81,84,109,111,135,153$ & & $0.55 \pm 0.52$ & - \\
\hline 16 & Unidentified iridoid $^{c}$ & 1407 & $84,109,111,166$ & & $1.48 \pm 0.98$ & $0.83 \pm 0.64$ \\
\hline 17 & Unknown compound & 1411 & $97,109,124,139$ & & $4.45 \pm 2.83$ & - \\
\hline 18 & $\begin{array}{l}4 R, 4 \mathrm{a} R, 7 R, 7 \mathrm{a} S \text {-dihydrone- } \\
\text { petalactone }\end{array}$ & 1417 & $67,81,95,110,113,153,168$ & & $9.34 \pm 4.92$ & $2.21 \pm 0.76$ \\
\hline 19 & $(+)$-Iridomyrmecin & 1450 & $67,81,95,109$ & & $2.55 \pm 1.32$ & $1.49 \pm 0.43$ \\
\hline 20 & Unknown iridoid & 1458 & $\begin{array}{l}67,81,95,110,113,126 \\
\quad 153,168\end{array}$ & & $25.29 \pm 13.97$ & $4.58 \pm 1.48$ \\
\hline 21 & $n$-Hexadecanoic acid & 1961 & $57,60,73,129,213,256$ & & $0.87 \pm 2.02$ & - \\
\hline 22 & 4-Methyl tetracosane & 2461 & $\begin{array}{l}\text { 71, 309, } 337(\mathrm{M}-15), 352 \\
(\mathrm{M}+)\end{array}$ & & $0.54 \pm 0.82$ & - \\
\hline 23 & 4-Methyl hexacosane & 2661 & $337,365(\mathrm{M}-15), 380(\mathrm{M}+)$ & & $1.62 \pm 1.35$ & - \\
\hline 24 & 7,x,x-Trimethyl heptacosane & 2785 & $113,253,337$ & & $0.95 \pm 1.28$ & $2.33 \pm 2.03$ \\
\hline 25 & $\mathrm{x}, \mathrm{x}$-Nonacosadiene & 2837 & $96,404(\mathrm{M}+)$ & & $1.54 \pm 1.27$ & $0.83 \pm 1.11$ \\
\hline 26 & 4-Methyl octacosane & 2861 & $\begin{array}{l}\text { 71, 365, } 393(\mathrm{M}-15), 408 \\
(\mathrm{M}+)\end{array}$ & & $8.26 \pm 5.29$ & $9.11 \pm 4.96$ \\
\hline 27 & 9-Nonacosene & 2877 & $97,253,281,406(\mathrm{M}+)$ & $173,327,500(\mathrm{M}+)$ & $7.96 \pm 5.76$ & $8.81 \pm 5.49$ \\
\hline 28 & 7-Nonacosene & 2884 & $97,406(\mathrm{M}+)$ & 145,355 & $5.98 \pm 3.57$ & - \\
\hline 29 & Unknown CHC & 2898 & $253,341,408(\mathrm{M}+)$ & & - & $0.56 \pm 0.78$ \\
\hline 30 & $\begin{array}{l}\text { 13-Methyl nonacosane; } \\
\text { 15-methyl nonacosane }\end{array}$ & 2927 & $196 / 7,252 / 3 ; 224 / 5$ & & $2.20 \pm 1.78$ & $0.59 \pm 0.82$ \\
\hline 31 & 4-Methyl nonacosane & 2959 & 378/9, 407 (M-15), $422(\mathrm{M}+)$ & & $2.80 \pm 1.37$ & $3.08 \pm 0.93$ \\
\hline 32 & $\begin{array}{l}\text { 5,11-Dimethyl nonacosane; } \\
\text { 5,17-dimethyl nonacosane }\end{array}$ & 2977 & $\begin{array}{l}85,183,281,379,421 \\
\quad(\mathrm{M}-15) ; 85,197,267,379 \\
421(\mathrm{M}-15)\end{array}$ & & $1.76 \pm 2.06$ & - \\
\hline 33 & $\begin{array}{l}\text { 14-Methyl triacontane; } \\
\text { 15-methyl triacontane }\end{array}$ & 3028 & $\begin{array}{l}211,253,421(\mathrm{M}-15), 434 \\
(\mathrm{M}+) ; 225,239,421 \\
(\mathrm{M}-15), 434(\mathrm{M}+)\end{array}$ & & $0.53 \pm 1.03$ & - \\
\hline 34 & $\mathrm{x}, \mathrm{x}$-Hentriacontadiene & 3048 & $96,432(\mathrm{M}+)$ & & $7.26 \pm 6.42$ & - \\
\hline 35 & $\mathrm{x}, \mathrm{x}$-Hentriacontadiene & 3051 & $96,432(\mathrm{M}+)$ & & $3.92 \pm 5.37$ & - \\
\hline 36 & 4-Methyl triacontane & 3060 & $393,421(\mathrm{M}-15), 436(\mathrm{M}+)$ & & $157.22 \pm 57.99$ & $186.39 \pm 34.78$ \\
\hline 37 & 9-Hentriacontene & 3078 & $97,434(\mathrm{M}+)$ & $173,355,528(\mathrm{M}+)$ & $98.21 \pm 59.67$ & $52.63 \pm 14.75$ \\
\hline 38 & 7-Hentriacontene & 3085 & $97,434(\mathrm{M}+)$ & $145,383,528(\mathrm{M}+)$ & $46.33 \pm 33.35$ & $19.48 \pm 5.71$ \\
\hline
\end{tabular}


Table 1 (continued)

\begin{tabular}{|c|c|c|c|c|c|c|}
\hline No & Compound & KRI & Diagn. Ions & Diagn. Ions DMDS & $\begin{array}{l}\text { Mean amount } \\
(\mathrm{ng} \pm \mathrm{SD}) \text { per } \\
\text { female }\end{array}$ & $\begin{array}{l}\text { Mean amount } \\
(\mathrm{ng} \pm \mathrm{SD}) \text { per } \\
\text { male }\end{array}$ \\
\hline 39 & Putative cholesterol & 3097 & $255,275,386$ & & $1.09 \pm 1.88$ & - \\
\hline 40 & $\begin{array}{l}\text { 13-Methyl hentriacontane; } \\
\text { 15-methyl hentriacontane }\end{array}$ & 3126 & $196 / 7,280 / 1 ; 224 / 5,252 / 3$ & & $7.41 \pm 6.55$ & $4.30 \pm 3.68$ \\
\hline 41 & Unknown compound $\mathrm{d}^{\mathrm{c}, \mathrm{d}}$ & 3137 & $275,301,386,353,368$ & & $5.31 \pm 2.94$ & $8.82 \pm 2.95$ \\
\hline 42 & 4-Methyl hentriacontane & 3158 & $\begin{array}{l}281,386,407,435 \text { (M-15), } \\
\quad 450\end{array}$ & & $0.41 \pm 0.57$ & - \\
\hline 43 & $\mathrm{x}$-Methyl dotriacontane & 3176 & $\begin{array}{l}85,253,281,351,407,449 \\
\quad(\mathrm{M}-15)\end{array}$ & & $1.08 \pm 1.09$ & - \\
\hline 44 & $\begin{array}{l}\text { 14-Methyl dotriacontane; } \\
\text { 15-methyl dotriacontane }\end{array}$ & 3232 & $\begin{array}{l}211,281,449(\mathrm{M}-15), 464 \\
(\mathrm{M}+) ; 225,267,449 \\
(\mathrm{M}-15), 464(\mathrm{M}+)\end{array}$ & & $5.44 \pm 7.53$ & $2.04 \pm 2.61$ \\
\hline 45 & 7,17-Tritriacontadiene & 3249 & $96,460(\mathrm{M}+)$ & $\begin{array}{l}145,271,283,409,455,507 \\
(\mathrm{M}-141), 554(\mathrm{M}-94), 648 \\
(\mathrm{M}+)\end{array}$ & $35.33 \pm 23.83$ & $19.10 \pm 8.36$ \\
\hline 46 & 4-Methyl dotriacontane & 3258 & 449 (M-15), 421 & & $21.50 \pm 11.54$ & $32.68 \pm 12.32$ \\
\hline 47 & $\mathrm{x}$-Tritriacontene & 3278 & $97,462(\mathrm{M}+)$ & & $16.35 \pm 11.90$ & $12.60 \pm 12.82$ \\
\hline 48 & $\mathrm{x}$-Tritriacontene & 3286 & $97,462(\mathrm{M}+)$ & & $1.35 \pm 2.02$ & $2.21 \pm 1.40$ \\
\hline 49 & $\mathrm{x}$-Tetratriacontene & 3319 & $97,476(\mathrm{M}+)$ & & $1.55 \pm 2.84$ & $4.16 \pm 4.71$ \\
\hline 50 & $\begin{array}{l}\text { 13-Methyl tritriacontane; } \\
\text { 15-methyl tritriacontane; } \\
\text { 17-methyl tritriacontane }\end{array}$ & 3325 & 197,$309 ; 225,281 ; 253$ & & $5.73 \pm 7.13$ & $2.48 \pm 3.33$ \\
\hline 51 & 9,19-Pentatriacontadiene & 3449 & $96,488(\mathrm{M}+)$ & $\begin{array}{c}173,271,311,409,535 \\
(\mathrm{M}-141), 676(\mathrm{M}+)\end{array}$ & $20.09 \pm 12.33$ & $136.01 \pm 39.84$ \\
\hline 52 & $\begin{array}{l}x, x-P e n t a t r i a c o n t a d i e n e \\
\text { Total amount }\end{array}$ & 3450 & $96,488(\mathrm{M}+)$ & & $\begin{array}{l}8.01 \pm 17.49 \\
870.98 \pm 339.54\end{array}$ & $\begin{array}{l}- \\
607.73 \pm 126.48\end{array}$ \\
\hline
\end{tabular}

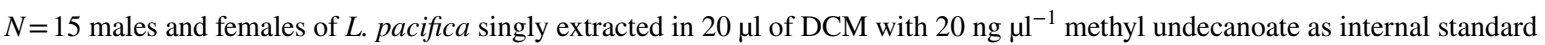

KRI Kovats retention index on a non-polar DB-5 GC column. Diagn. Ions diagnostic ions used in the identification of the compound. Diagn. Ions DMDS diagnostic ions of unsaturated compounds after derivatization with DMDS. $x=$ The position of methyl branch(es) and/or double bond(s) could not be determined. Numbers of compounds correspond to Fig. 2

${ }^{a}$ Compound also found in L. boulardi (Weiss et al. 2015a)

${ }^{\mathrm{b}}$ Unknown absolute configuration

${ }^{c}$ Compound also found in L. japonica (Böttinger et al. 2019)

${ }^{\mathrm{d}}$ Compound also found in L. ryukyuensis (Böttinger et al. 2019)

${ }^{\mathrm{e}}$ Compound also found in Alloxysta victrix (Zimmermann et al. 2012)

context when left undisturbed, but when attacked by the $C$. carnea larvae, they released on average $7.33 \mathrm{ng} \pm 12.63 \mathrm{ng}$ (mean $\pm \mathrm{SD}$ ), a significant increase (Mann-Whitney $U$ test, $W=64, P=0.045$, Fig. 3).

The intensity of the attack by the $C$. carnea larvae was highly variable. Therefore, we measured the amount of released deterrent compounds of L. pacifica females when teased with a small magnetic stir bar, instead of being attacked by the larvae. Females released on average $0.40 \pm 1.14 \mathrm{ng}$ (mean $\pm \mathrm{SD}$ ) of total iridoids and citral components when left undisturbed, but when teased with the magnetic stir bar, the amount of iridoids and citral components released increased significantly to
$8.89 \pm 17.13 \mathrm{ng}($ mean $\pm \mathrm{SD}$; Mann-Whitney $U$ test, $W=9$, $P<0.001$, Fig. 4).

\section{Competition avoidance of females}

Mated host-searching female L. pacifica did not avoid the odor of conspecific female wasps in the Y-tube olfactometer when given the choice between the odor of unexploited host patches and host patches occupied by 20 living conspecific females ( $P=0.86$, Fig. 5). However, $L$. pacifica females avoided the odor of the host patch, when the extract of $L$. pacifica females instead of living females was added to the host patch odor $(P<0.01$, Fig. 5). 
(a) L. pacifica females

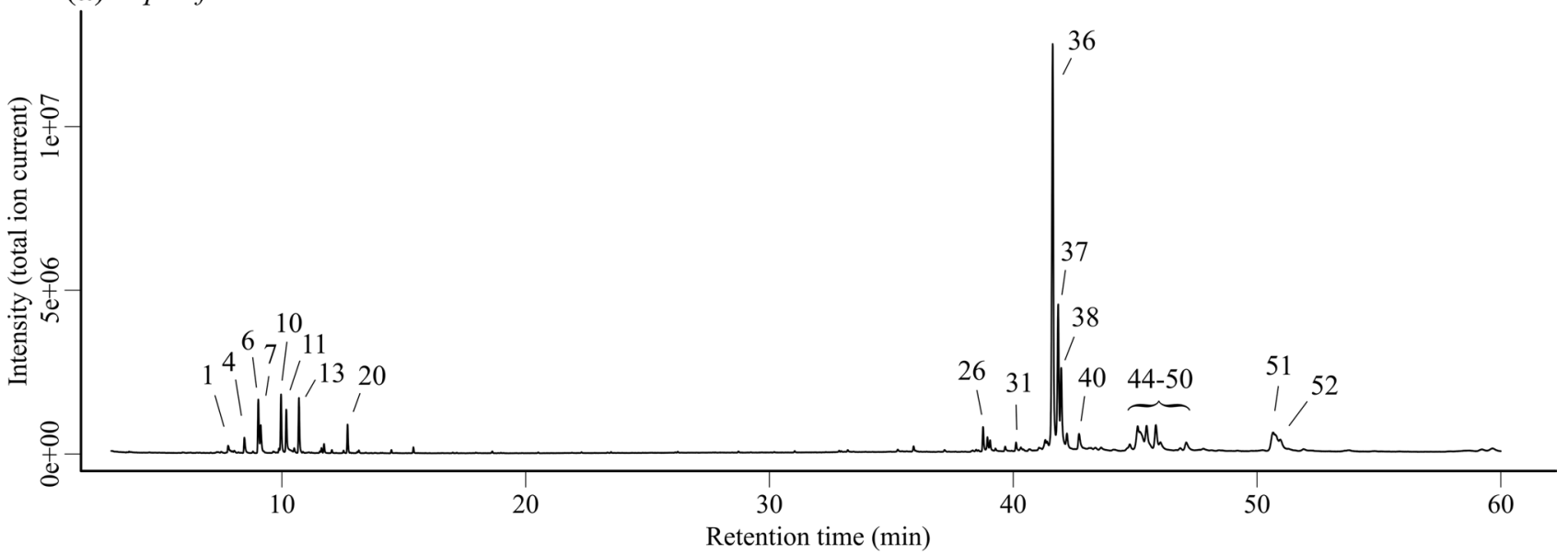

(b) L. pacifica males

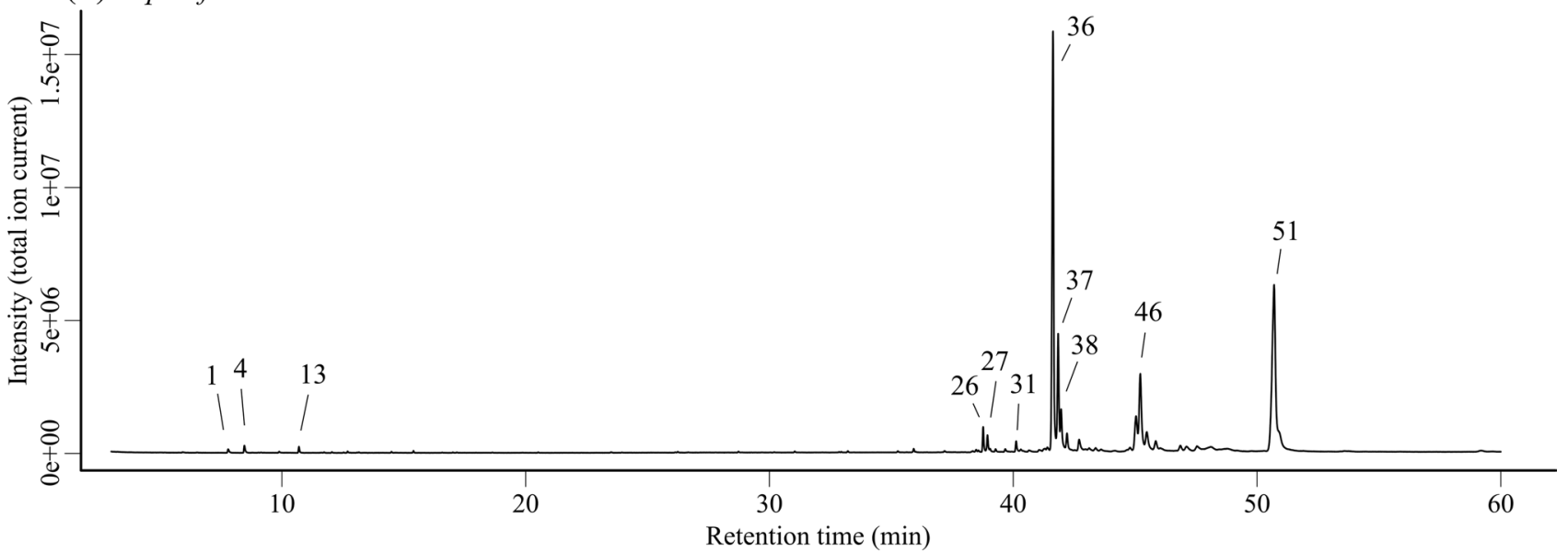

Fig. 2 Chemical compounds produced by L. pacifica wasps. Total ion current chromatograms of extracts of a $L$. pacifica females and b $L$. pacifica males, analyzed on a non-polar DB-5 GC column. Peak numbers correspond to Table 1

\section{Sex pheromone}

To investigate the compounds of females that are used by males to find and court mating partners, female extracts, fractions thereof and solvent control were applied on filter paper discs and presented to males. Male wasps of $L$. pacifica showed courtship behavior, i.e., wing fanning, when presented with the odor of conspecific females. The longest duration of wing fanning was displayed towards the whole body extracts of female L. pacifica wasps; however, there was no statistical difference in the duration of wing fanning exhibited when males were presented only with the females' CHCs present in the hexane fraction of female extracts (Kruskal-Wallis test, chi-squared $=53.577, d f=3$, $P<0.001$, Fig. 6). The solvent control, as well as the iridoid compounds contained in the DCM fraction of extracts of females, elicited significantly less wing fanning. The $\mathrm{CHCs}$ serve, therefore, as the female sex pheromone in L. pacifica.

\section{Discussion}

Weiss et al. (2013) recently found that the parasitoid wasp $L$. heterotoma relies on a single iridoid compound for several functions, allowing them to reconstruct the evolution of pheromone communication in this species. The compound (-)-iridomyrmecin serves in this species as a defensive secretion (Stökl et al. 2012), as a cue for females to avoid competition during host search, and as the main component of the female sex pheromone (Weiss et al. 2013, see Fig. 1). All Leptopilina species studied to date produce iridoids for defense (Stökl et al. 2012; Weiss et al. 2013, 2015a; Pfeiffer et al. 2018; Böttinger et al. 2019), but only three species use the iridoids in their female sex pheromone (Weiss et al. 2013, 2015a; Böttinger et al. 2019; Fig. 1). It is assumed, therefore, that defense is the primary function of these iridoid compounds, and that their use as sex pheromones to attract mates evolved 


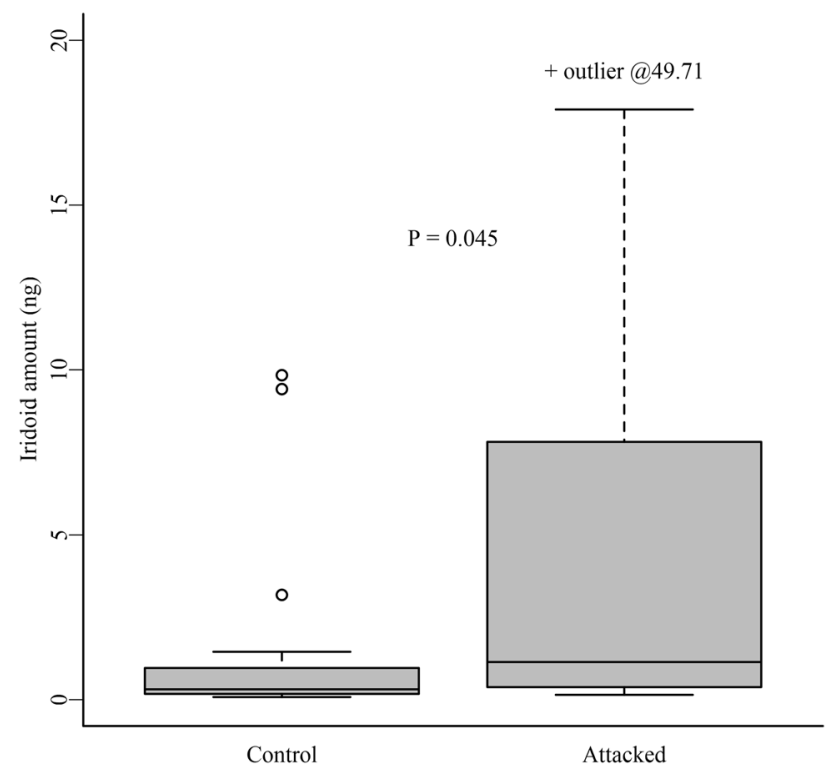

Fig. 3 Iridoids for defense released upon attack. Box-and-whisker plots showing median (horizontal line), inter-quartile range (box), outliers (unfilled circles), and maximum/minimum of the $1.5 \times$ interquartile range (whiskers) of the released iridoid amounts (ng) of two females of L. pacifica in a small vial when left alone (Control) or when attacked 5 min from a lacewing larva (Attacked). $P$ values are given for Mann-Whitney $U$ tests. Each experiment $N=15$

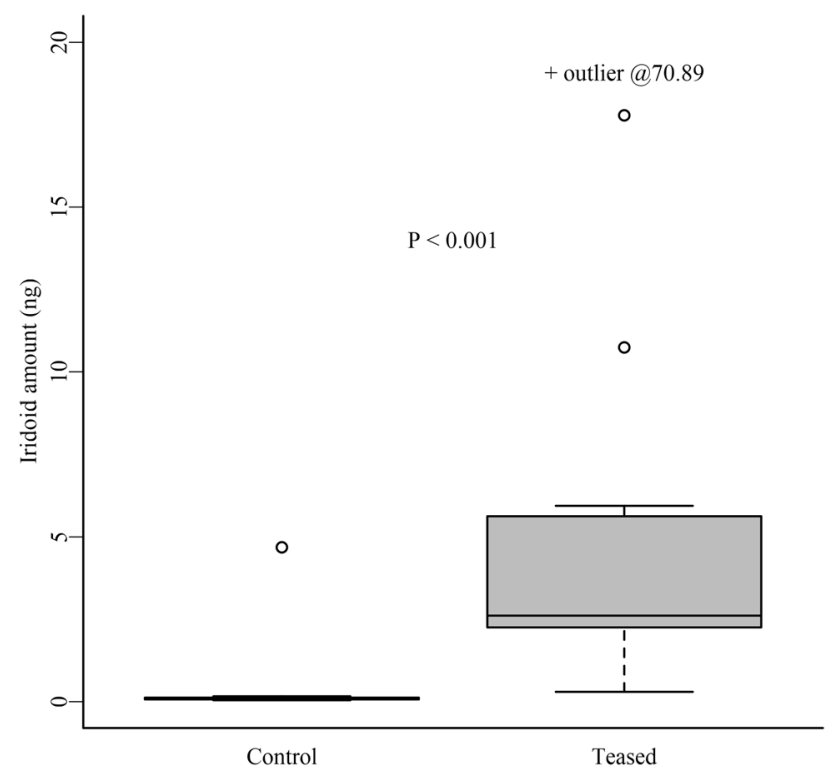

Fig. 4 Iridoids for defense released upon teasing. Box-and-whisker plots showing median (horizontal line), inter-quartile range (box), outliers (unfilled circles), and maximum/minimum of the $1.5 \times$ interquartile range (whiskers) of the released iridoid amounts (ng) of two females of L. pacifica in a small vial when left alone (Control) or when slightly teased 10 times in 5 min with a small magnetic stir bar (Teased). $P$ values are given for Mann-Whitney $U$ tests. Each experiment $N=15$

\section{Decisions of female wasps}

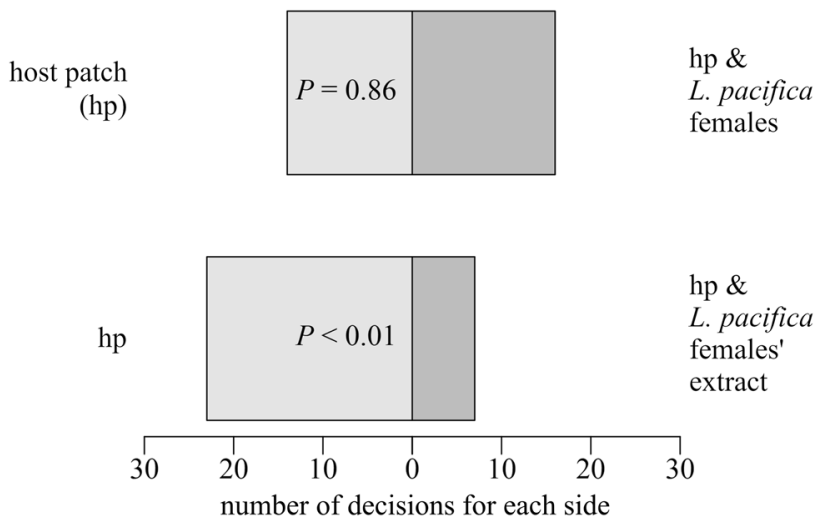

Fig. 5 Competition avoidance of females. Frequency of decision for control (light grey bars) or sample (dark grey bars) of females of $L$. pacifica in a Y-tube experiment when choosing between the odor of unexploited host patches (hp) or host patches with either 20 conspecific females or the extract of conspecific females. $P$ values are given for two-sided binomial tests. Each experiment $N=30$

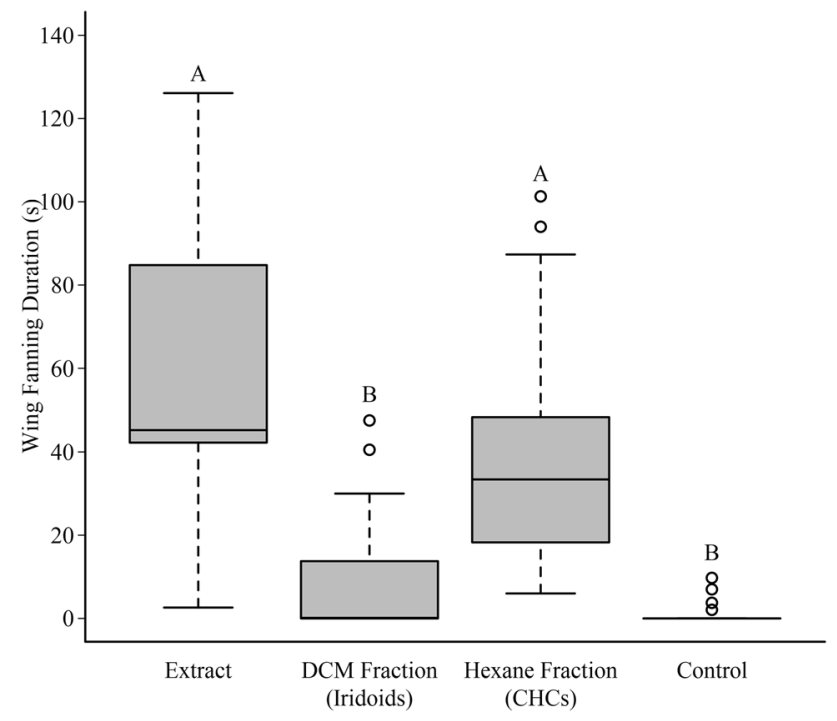

Fig. 6 Female sex pheromone. Box-and-whisker plots showing median (horizontal line), inter-quartile range (box), outliers (unfilled circles), and maximum/minimum of the $1.5 \times$ inter-quartile range (whiskers) of the duration of courtship behavior (i.e., wing fanning) displayed by males of $L$. pacifica towards whole body extracts of conspecific females, as well as towards the iridoid containing DCM fractions and the $\mathrm{CHC}$ containing hexane fractions of the female extracts and the solvent control. Different letters indicate a significant difference (Kruskal-Wallis ANOVA followed by pairwise Mann-Whitney $U$ tests with Bonferroni-Holm correction, $P<0.05)$. Each experiment $N=20$

as a secondary function in L. heterotoma females (Weiss et al. 2013). Here, we investigated whether the evolution of pheromone communication led to a comparable result in 
L. pacifica, the sister species of L. heterotoma (Novković et al. 2011; Wachi et al. 2015). Accordingly, we analyzed the chemical compounds produced by males and females, and the functions these compounds fulfill in communication in this species. Our results indeed show that $L$. pacifica wasps also produce several iridoid compounds and use them as defensive secretion. However, in contrast to female L. heterotoma, female L. pacifica do not avoid host patches occupied by conspecifics and do not use the iridoids in their sex pheromone, relying on CHCs instead (Fig. 1).

Congruent with chemical analyses of $L$. heterotoma (Stökl et al. 2012), the predominant volatile compounds of L. pacifica wasps were iridoid substances. However, the variety of different iridoid compounds produced by $L$. pacifica females is higher than in any other species of the genus Leptopilina (Table 1; Fig. 2; Stökl et al. 2012; Weiss et al. 2013, 2015a; Pfeiffer et al. 2018; Böttinger et al. 2019). Instead of having one main iridoid compound, as in L. heterotoma, where the compound (-)-iridomyrmecin constitutes more than $80 \%$ of the volatiles of females (Stökl et al. 2012; Weiss et al. 2015a), females of $L$. pacifica produce a complex mixture of different iridoid compounds with six iridoids being produced in similar amounts (Table 1). Interestingly, iridomyrmecin is not found among these six, which is in contrast to all other species of Leptopilina studied thus far. Furthermore, we found a differing stereochemistry of iridomyrmecin in $L$. pacifica; females and males produce (+)-iridomyrmecin. Most species, including L. heterotoma and L. boulardi, produce (-)-iridomyrmecin, while its enantiomer (+)-iridomyrmecin has been found in only two species thus far (Fig. 1). Additionally, we found citral, which is a mixture of the terpenoid cis-trans-isomers (Z)-3,7-dimethyl2,6-octadienal (neral) and (E)-3,7-dimethyl-2,6-octadienal (geranial) in the extracts of L. pacifica wasps. Citral has not been found in any other species of Leptopilina.

The CHCs produced by male and female L. pacifica consisted mainly of mono- and di-unsaturated alkanes or methyl branched alkanes and, although they qualitatively resemble a number of the CHCs found in other species of the genus (Table 1; Fig. 2; Weiss et al. 2013, 2015a; Pfeiffer et al. 2018; Böttinger et al. 2019), their qualitative and quantitative composition is species specific. Extracts of male $L$. pacifica contained high amounts of 9,19-pentatriacontadiene, which seems to be a compound typically found in males of the genus Leptopilina. This compound was found in large amounts in male L. japonica and L. ryukyuensis (Böttinger et al. 2019), as well in L. clavipes and L. heterotoma (Weiss et al. 2015b; Pfeiffer et al. 2018). 9,19-pentatriacontadiene presumably comprises a part of the species-specific male antennal aphrodisiac pheromone that gets transferred between the male and female antennae during courtship to elicit readiness for mating in conspecific females (Isidoro et al. 1999; Weiss et al. 2015b).

In two different dynamic headspace analyses, we investigated which compounds get emitted by female $L$. pacifica when they are attacked. First, we determined which compounds get emitted by wasps when they are attacked by larval $C$. carnea, representing attacks from natural enemies. We found significantly more iridoid and citral compounds in headspace analyses of attacked wasps than of undisturbed control wasps; thus, the present study clearly demonstrates that these compounds are used for defense. However, we found wasps emitting different amounts of deterrent compounds in each run of the experiment. This was possibly due to the variation in the intensity of the attacks by the $C$. carnea larvae, as they sometimes heavily attacked the wasps, while other larvae did not attack the wasps at all. Therefore, in a second experiment, we simulated natural attacks in a standardized experimental design by teasing the wasps with a magnetic stir bar, leading again to emissions of females' citral and iridoids. As both experiments led to similar amounts of released defensive secretions, but with a lower variation in the stir bar experiment, the standardized experiment may provide a more sensitive test for assessing the deterrent compounds of small insects than the natural predator attack experiment. Iridoids are typical defensive compounds that are used for defense in several insect species. Iridomyrmecin and two iridodials were first isolated from the defensive secretion of the ant Iridomyrmex humilis (Pavan 1952; Cavill et al. 1976). Furthermore, iridoid compounds such as iridodials, iridomyrmecin, actinidine and nepetalactone were found to be used for defense in chrysomelid beetle larvae (e.g., Sugawara et al. 1979; Pasteels et al. 1982; Veith et al. 1994), aphids (Dawson et al. 1987), thrips (Tschuch et al. 2008), stick insects (Meinwald et al. 1962; Smith et al. 1979; Chow and Lin 1986; Prescott et al. 2009), in the parasitic wasp genus Alloxysta (Hymenoptera, Charipidae) (Völkl et al. 1994; Petersen 2000), ants (Wheeler et al. 1977; Tomalski et al. 1987), as well as in various staphylinid species (Bellas et al. 1974). Also citral, whose occurrence we show here for the first time in a species of Leptopilina, is used as an alarm pheromone in mites (e.g., Kuwahara et al. 1980, 1983; Raspotnig 2006) and as an alarm releaser and compound of the defensive secretion in ants, such as Acanthomyrmex claviger (Ghent 1961) and Atta sexdens (Butenandt et al. 1959; Blum et al. 1968). We conclude, therefore, that defense is the primary function of iridoid and citral compounds in Leptopilina. The amounts of emitted deterrent volatiles in both attack or simulated predatory disturbances were found in quantitatively lower amounts than in the total body extracts of female L. pacifica (see Figs. 3 and 4 and Table 1). However, we cannot assume wasps would entirely deplete their 
defensive compound arsenal upon an attack, but rather emit an amount of deterrent secretions just sufficient to deter the attacking enemy and escape the dangerous situation (Stökl et al. 2015). The physiological mode of action of these emitted iridoid compounds is probably similar to that of iridoid glycosides, which denatures proteins and nucleic acids (Dobler et al. 2011). Wasps of the genus Leptopilina were previously shown to be able to adjust the amounts of emitted allomones depending on the size of their attacking enemy (Stökl et al. 2015), which could explain why we found different amounts of deterrent compounds in the different runs of the attack experiment (Fig. 3).

Although members of the same genus often have similar chemical compounds due to shared biosynthetic pathways (Tillman et al. 1999), and closely related species often use the same main pheromonal compounds (Smadja and Butlin 2009), pheromones of sister species can be considerably different (Symonds and Elgar 2008; Menzel et al. 2017; Butterworth et al. 2020). Indeed, studies found substantially different compositions of the volatile defensive compounds not only between the sister species L. heterotoma and $L$. pacifica, but within the whole genus Leptopilina (Stökl et al. 2012, 2015; Weiss et al. 2013, 2015a; Pfeiffer et al. 2018; Böttinger et al. 2019; this study). There is extensive variation in the quantity of different deterrent compounds, ranging from basically one main predominant compound (-)-iridomyrmecin in L. heterotoma, L. boulardi (Stökl et al. 2012, 2015; Weiss et al. 2015a), and L. clavipes (Pfeiffer et al. 2018), to the more complex array of iridoids in L. victoriae (Weiss et al. 2015a) and L. japonica (Böttinger et al. 2019), and peaking in the complex mixture of citral and iridoid compounds found here in L. pacifica. This is surprising, as we would predict only modest interspecific variation in the composition of defensive secretions, as individuals should benefit from the recognition of defensive secretions of conand hetero-specifics. Therefore, species-specificity of these deterrent compounds should not be necessary and selection on interspecific variation of deterrent compounds and alarm cues should be low (Regnier and Law 1968; Blum 1969; Vander Meer and Le Alonso 1998). However, although there are several examples of interspecifically identical defensive or alarm substances in ants (Wilson and Pavan 1959), pentatomid stink bugs (Ishiwatari 1974), and aphids (Vandermoten et al. 2012), extensive variation in alarm pheromone composition among closely related leaf-cutting ant species has recently been documented (Norman et al. 2017). Interspecific variation of the volatile defensive secretion within the genus Leptopilina suggests, therefore, that iridoid compounds serve not only for defense but also other purposes, e.g., as sex pheromone.

In L. heterotoma (Weiss et al. 2013), L. clavipes (Pfeiffer et al. 2018), L. boulardi (unpublished) and L. ryukyuensis
(Böttinger et al. 2019), female wasps avoided competition with conspecific females (Fig. 1). This competition avoidance is mediated by the females' emissions of iridoid volatiles even in undisturbed situations during egg-laying. In $L$. pacifica, no such avoidance behavior was observed in the experiment using live females. However, we found a significant avoidance of the odor of the host patch with the females' extract (as opposed to live females). Thus, female $L$. pacifica have the potential to exhibit avoidance behavior, but it was not triggered in our experimental setting. This could be explained by the relatively lower emission of the deterrent iridoid and citral volatile compounds of undisturbed wasps of $L$. pacifica, as can be seen in the control wasp headspace analyses (Figs. 3 and 4). It remains possible that a higher number of females on the host patch would trigger the avoidance behavior. However, the number of females on the host patch was already quite high (20 females). It seems plausible, therefore, that under natural conditions, females on the host patch do not emit enough volatiles to elicit the avoidance behavior in searching females. The positive result we found using the females' extract might then be regarded as an artefact. Interestingly, females of the sister species L. heterotoma show a clear avoidance of live conspecific females (Weiss et al. 2013). The lack of avoidance behavior in $L$. pacifica could indicate that this species is more competitive and does not need to avoid superparasitism. Alternatively, the amount of iridoids in the extract presented to the female subjects might have resembled the odor of attacked or dead conspecifics. Under this scenario, the females avoided the host patch not because of anticipated competition with other females, but because of the danger of a predatory attack.

Iridoid compounds serve not only as a deterrent secretion and a cue for female competition avoidance in L. heterotoma, but also as the main component of the female sex pheromone (Stökl et al. 2012; Weiss et al. 2013). As speciation of the sister species L. heterotoma and L. pacifica may have been accompanied by a differentiation of sex pheromones, we aimed in this study to analyze the sex pheromone compounds of $L$. pacifica females. We found that the sex pheromone of female L. pacifica wasps consists of CHC compounds, whereas the iridoid compounds and citral are not needed to elicit courtship behavior in males. This is in contrast to the sister species L. heterotoma, in which females' CHCs elicited almost no interest of males, whereas the iridoids (with (-)-iridomyrmecin as main component) triggered courtship behavior of males (Weiss et al. 2013, 2015a). This stark divergence in female sex pheromones could be the result of a saltational shift during speciation as observed in several other insect species (bark beetles: e.g., Symonds and Elgar 2004; wasps: e.g., Buellesbach et al. 2013; ants: e.g., Menzel et al. 2017; blowflies: e.g., Butterworth et al. 2020; stick insects: e.g., 
Schwander et al. 2013). Even within the same class of compounds (iridoids or $\mathrm{CHCs}$ ), a saltational shift in pheromone composition is easily achievable. As such, the switch from iridoids to CHCs may be explained by selection for either long-range attracting volatile iridoids or short-range $\mathrm{CHCs}$ depending on differences in the mating system of the species. Species mating directly on the host patch on which they emerge would not have the necessity of a longrange sex pheromone, and a CHC-based sex pheromone would be sufficient to ensure sex and species recognition. In contrast, species with high dispersal rates after hatching would not be able to find their mates if they relied on low volatile $\mathrm{CHC}$ sex pheromones for orientation. These species must have evolved a volatile sex pheromone ranging over longer distances, a function for which the iridoid compounds are well suited. Support for this hypothesis was recently found in the species L. heterotoma, L. japonica, L. pacifica, and L. ryukyuensis (Böttinger and Stökl 2020). The dispersal behavior of male wasps correlated with the volatility of the female sex pheromones, with males of species with volatile iridoid sex pheromones, $L$. heterotoma and L. japonica, starting to disperse directly after emergence. In contrast, male wasps of species with CHC-based sex pheromones, L. pacifica and L. ryukyuensis, delayed their dispersal until the emergence of conspecific females (Böttinger and Stökl 2020). A comparative genetic and ecological analysis approach would help to disentangle the role of the selective forces shaping the evolution of pheromone usage in the genus Leptopilina.

Acknowledgements The authors wish to thank Prof. M. T. Kimura (Hokkaido University, Japan) for providing us with $L$. pacifica wasps, and Prof. John Hofferberth, who synthesized the compound (+)-iridomyrmecin we used in this study. We are grateful to Prof. Scott Sakaluk and Prof. John Hofferberth for their useful comments and suggestions that helped improve the manuscript.

Author contributions LB and JS conceived and designed the research plan. LB performed the quantitative and qualitative chemical analyses as well as the chemical defense experiment. FH conducted the behavioral analyses for the sex pheromones and the female competition avoidance. LB and FH analyzed the data. LB wrote the manuscript. JS edited and all authors approved the manuscript.

Funding Open Access funding enabled and organized by Projekt DEAL.. Open Access funding enabled and organized by Projekt DEAL. This work was supported by grants from the German Research Foundation DFG (STO 966/1-2 and STO 966/2-1).

\section{Compliance with ethical standards}

Conflicts of interest/Competing interests The authors declare that they have no conflict of interest.

Open Access This article is licensed under a Creative Commons Attribution 4.0 International License, which permits use, sharing, adaptation, distribution and reproduction in any medium or format, as long as you give appropriate credit to the original author(s) and the source, provide a link to the Creative Commons licence, and indicate if changes were made. The images or other third party material in this article are included in the article's Creative Commons licence, unless indicated otherwise in a credit line to the material. If material is not included in the article's Creative Commons licence and your intended use is not permitted by statutory regulation or exceeds the permitted use, you will need to obtain permission directly from the copyright holder. To view a copy of this licence, visit http://creativecommons.org/licenses/by/4.0/.

\section{References}

Allemand R, Lemaitre C, Frey F, Boulétreau M, Vavre F, Nordlander G, van Alphen JJM, Carton Y (2002) Phylogeny of six African Leptopilina species (Hymenoptera: Cynipoidea, Figitidae), parasitoids of Drosophila, with description of three new species. Ann Soc Entomol Fr 38:319-332

Bellas TE, Brown WV, Moore BP (1974) The alkaloid actinidine and plausible precursors in defensive secretions of rove beetles. $\mathrm{J}$ Insect Physiol 20:277-280

Benjamini Y, Hochberg Y (1995) Controlling the false discovery rate: a practical and powerful approach to multiple testing. J Roy Stat Soc B 57:289-300

Blum MS (1969) Alarm pheromones. Annu Rev Entomol 14:57-80. https://doi.org/10.1146/annurev.en.14.010169.000421

Blum MS (1996) Semiochemical parsimony in the Arthropoda. Annu Rev Entomol 41:353-374. https://doi.org/10.1146/annur ev.en.41.010196.002033

Blum MS, Padovani F, Amante E (1968) Alkanones and terpenes in the mandibular glands of Atta species (Hymenoptera: Formicidae). Comp Biochem Physiol 26:291-299

Bordereau C, Pasteels JM (2011) Pheromones and chemical ecology of dispersal and foraging in termites. In: Bignell DE, Roisin Y, Lo N (eds) Biology of termites: a modern synthesis. Springer Netherlands, Dordrecht, pp 279-320

Böttinger LC, Stökl J (2020) Dispersal from natal patch correlates with the volatility of female sex pheromones in parasitoid wasps. Front Ecol Evol. https://doi.org/10.3389/fevo.2020.557527

Böttinger LC, Hofferberth J, Ruther J, Stökl J (2019) Semiochemicals mediating defense, intraspecific competition, and mate finding in Leptopilina ryukyuensis and L. japonica (Hymenoptera: Figitidae), parasitoids of Drosophila. J Chem Ecol 45:241-252. https://doi.org/10.1007/s10886-019-01052-w

Bradbury JW, Vehrencamp SL (2011) Principles of animal communication. Sinauer Associates, Sunderland

Buellesbach J, Gadau J, Beukeboom LW, Echinger F, Raychoudhury R, Werren JH, Schmitt T (2013) Cuticular hydrocarbon divergence in the jewel wasp Nasonia: evolutionary shifts in chemical communication channels? J Evol Biol. https://doi. org/10.1111/jeb. 12242

Butenandt A, Linzen B, Lindauer MT (1959) Über einen Duftstoff aus der Mandibeldrüse der Blattschneiderameise Atta sexdens rubropilosa Forel. Arch Anat Microsc Morphol Exp 48:13-19

Butterworth NJ, Wallman JF, Drijfhout FP, Johnston NP, Keller PA, Byrne PG (2020) The evolution of sexually dimorphic cuticular hydrocarbons in blowflies (Diptera: Calliphoridae). J Evol Biol 33(10):1468-1486. https://doi.org/10.1111/jeb.13685

Carlson DA, Roan CS, Yost RA, Hector J (1989) Dimethyl disulfide derivatives of long chain alkenes, alkadienes, and alkatrienes for gas chromatography/mass spectrometry. Anal Chem 61:15641571. https://doi.org/10.1021/ac00189a019

Carlson DA, Bernier UR, Sutton BD (1998) Elution patterns from capillary GC for methyl-branched alkanes. J Chem Ecol 24:1845-1865. https://doi.org/10.1023/A:1022311701355 
Carton Y, Boulétreau M, van Alphen JJM, van Lenteren JC (1986) The Drosophila parasitic wasps. In: Ashburner M, Carson HL, Thompson JN (eds) The genetics and biology of Drosophila. Academic Press, Orlando, pp 347-394

Cavill GWK, Houghton E, McDonald FJ, Williams PJ (1976) Isolation and characterization of dolichodial and related compounds from the argentine ant, Iridomyrmex humilis. Insect Biochem 6:483-490. https://doi.org/10.1016/0020-1790(76)90072-X

Chow YS, Lin YM (1986) Actinidine, a defensive secretion of stick insect, Megacrania alpheus Westwood (Orthoptera: Phasmatidae). Journal of Entomological Science 21:97-101

Dawson GW, Griffiths DC, Janes NF, Mudd A, Pickett JA, Wadhams LJ, Woodcock CM (1987) Identification of an aphid sex pheromone. Nature 325:614-616. https://doi.org/10.1038/325614a0

Dobler S, Petschenka G, Pankoke H (2011) Coping with toxic plant compounds-the insect's perspective on iridoid glycosides and cardenolides. Phytochemistry 72:1593-1604. https://doi. org/10.1016/j.phytochem.2011.04.015

El-Sayed AM (2020) The Pherobase: database of pheromones and semiochemicals. Available online at: www.pherobase.com

Friard O, Gamba M (2016) BORIS: a free, versatile open-source event-logging software for video/audio coding and live observations. Methods Ecol Evol 7:1325-1330. https://doi. org/10.1111/2041-210X.12584

Ghent RL (1961) Adaptive refinements in the chemical defense mechanisms of certain Formicinae. ( $\mathrm{PhD}$ thesis) Cornell University, Ithaca, New York

Ishiwatari T (1974) Studies on the scent of stink bugs (Hemiptera: Pentatomidae): I. Alarm pheromone activity. Appl Entomol Zool 9:153-158

Isidoro N, Bin F, Romani R, Pujade-Villar J, Ros-Farre P (1999) Diversity and function of male antennal glands in Cynipoidea (Hymenoptera). Zool Scr 28:165-174. https://doi.org/10.104 6/j.1463-6409.1999.00013.x

Jenni W (1951) Beitrag zur Morphologie und Biologie der Cynipide Pseudeucoila bochei Weld, eines Larvenparasiten von Drosophila melanogaster Meig. Acta Zool 32:177-254. https://doi. org/10.1111/j.1463-6395.1951.tb00468.x

Kimura MT, Suwito A (2012) Diversity and abundance of frugivorous drosophilids and their parasitoids in Bogor, Indonesia. J Nat Hist 46:1947-1957. https://doi.org/10.1080/00222933.2012.707239

Kuwahara Y, Matsumoto K, Wada Y (1980) Pheromone study on acarid mites IV. Citral: composition and function as an alarm pheromone and its secretory gland in four species of acarid mites. Med Entomol Zool 31:73-80

Kuwahara Y, Suzuki H, Matsumoto K, Wada Y (1983) Pheromone study on acarid mites XI. Function of mite body as geometrical isomerization and reduction of citral (the alarm pheromone). Appl Entomol Zool 18:30-39

Maynard Smith J, Harper D (2003) Animal signals. Oxford University Press, Oxford

Meinwald J, Chadha MS, Hurst JJ, Eisner I (1962) Defense mechanisms of arthropods IX. Anisomorphal, the secretion of a phasmid insect. Tetrahedron Lett 3:29-33. https://doi.org/10.1016/S0040 $-4039(00) 62038-5$

Menzel F, Schmitt T, Blaimer BB (2017) The evolution of a complex trait: cuticular hydrocarbons in ants evolve independent from phylogenetic constraints. J Evol Biol 30:1372-1385

Nelson DR (1993) Methyl-branched lipids in insects. In: Stanley DW, Nelson DR (eds) Insect lipids. University of Nebraska Press, Lincoln, pp 271-316

Norman VC, Butterfield T, Drijfhout F, Tasman K, Hughes WOH (2017) Alarm pheromone composition and behavioral activity in fungus-growing ants. J Chem Ecol 43:225-235
Novković B, Mitsui H, Suwito A, Kimura MT (2011) Taxonomy and phylogeny of Leptopilina species (Hymenoptera: Cynipoidea: Figitidae) attacking frugivorous Drosophilid flies in Japan, with description of three new species. Entomol Sci 14:333-346. https ://doi.org/10.1111/j.1479-8298.2011.00459.x

Pasteels JM, Braekman JC, Daloze D, Ottinger R (1982) Chemical defence in chrysomelid larvae and adults. Tetrahedron 38:18911897. https://doi.org/10.1016/0040-4020(82)80038-0

Pavan M (1952) Iridomyrmecin as insecticide. Trans IXth Int Congress of Entomol 1:321-327

Petersen G (2000) Signalstoffe in der innerartlichen Kommunikation des Hyperparasitoiden Alloxysta victrix (Hymenoptera: Cynipidae) und ihre Wirkung auf den Primärparasitoiden Aphidius uzbekistanicus und die Große Getreideblattlaus Sitobion avenae. (PhD Thesis) University of Kiel, Kiel

Pfeiffer L, Ruther J, Hofferberth J, Stökl J (2018) Interference of chemical defence and sexual communication can shape the evolution of chemical signals. Sci Rep 8:970. https://doi.org/10.1038/s4159 8-017-18376-w

Prescott TAK, Bramham J, Zompro O, Maciver SK (2009) Actinidine and glucose from the defensive secretion of the stick insect $\mathrm{Meg}$ acrania nigrosulfurea. Biochem Syst Ecol 37:759-760

R Core Team (2017) R: a language and environment for statistical computing. R Foundation for Statistical Computing, Vienna, Austria. Available online at: https://www.R-project.org

Raspotnig G (2006) Chemical alarm and defence in the oribatid mite Collohmannia gigantea (Acari: Oribatida). Exp Appl Acarol 39:177-194

Regnier FE, Law JH (1968) Insect pheromones. J Lipid Res 9:541-551

Schwander T, Arbuthnott D, Gries R, Gries G, Nosil P, Crespi BJ (2013) Hydrocarbon divergence and reproductive isolation in Timema stick insects. BMC Evol Biol 13:1-14

Smadja C, Butlin RK (2009) On the scent of speciation: the chemosensory system and its role in premating isolation. Heredity 102:77

Smith RM, Brophy JJ, Cavill GW, Davies NW (1979) Iridodials and nepetalactone in the defensive secretion of the coconut stick insects, Graeffea crouani. J Chem Ecol 5:727-735

Sorensen PW, Stacey NE (1999) Evolution and specialization of fish hormonal pheromones. In: Johnston RE, Müller-Schwarze D, Sorensen PW (eds) Advances in chemical signals in vertebrates. Kluwer Academic Publishers, New York, pp 15-47

Stacey N, Sorensen P (2011) Hormones in communication I hormonal pheromones. Encycl Fish Physiol 1:1553-1562. https://doi. org/10.1016/B978-0-12-374553-8.00137-4

Steiger S, Schmitt T, Schaefer HM (2011) The origin and dynamic evolution of chemical information transfer. Proc R Soc Lond B 278:970-979. https://doi.org/10.1098/rspb.2010.2285

Stökl J, Steiger S (2017) Evolutionary origin of insect pheromones. Curr Opin Insect Sci 24:36-42. https://doi.org/10.1016/j. cois.2017.09.004

Stökl J, Hofferberth J, Pritschet M, Brummer M, Ruther J (2012) Stereoselective chemical defense in the Drosophila parasitoid Leptopilina heterotoma is mediated by $(-)$-iridomyrmecin and (+)-isoiridomyrmecin. J Chem Ecol 38:331-339. https://doi. org/10.1007/s10886-012-0103-0

Stökl J, Machacek Z, Ruther J (2015) Behavioural flexibility of the chemical defence in the parasitoid wasp Leptopilina heterotoma. Sci Nat 102:67. https://doi.org/10.1007/s00114-015-1317-0

Sugawara F, Matsuda K, Kobayashi A, Yamashita K (1979) Defensive secretion of chrysomelid larvae Linaeidea aenea Linné and Plagiodera versicolora distincta Baly. J Chem Ecol 5:929-934. https ://doi.org/10.1007/BF00990215

Symonds MRE, Elgar MA (2004) The mode of pheromone evolution: evidence from bark beetles. Proc R Soc Lond B 271:839-846. https://doi.org/10.1098/rspb.2003.2647 
Symonds MRE, Elgar MA (2008) The evolution of pheromone diversity. Trends Ecol Evol 23:220-228. https://doi.org/10.1016/j. tree.2007.11.009

Tillman JA, Seybold SJ, Jurenka RA, Blomquist GJ (1999) Insect pheromones-an overview of biosynthesis and endocrine regulation. Insect Biochem Mol Biol 29:481-514. https://doi.org/10.1016/ S0965-1748(99)00016-8

Tomalski MD, Blum MS, Jones TH, Fales HM, Howard DF, Passera L (1987) Chemistry and functions of exocrine secretions of the ants Tapinoma melanocephalum and T. erraticum. J Chem Ecol 13:253-263. https://doi.org/10.1007/BF01025886

Tschuch G, Lindemann P, Moritz G (2008) An unexpected mixture of substances in the defensive secretions of the tubuliferan thrips, Callococcithrips fuscipennis (Moulton). J Chem Ecol 34:742-747

van den Assem J (1968) Reproductive behaviour of Pseudeucoila bochei (Hymenoptera: Cynipidae). Neth J Zool 19:641-649. https ://doi.org/10.1163/002829669X00080

Vander Meer RK, Le Alonso (1998) Pheromone directed behavior in ants. In: Vander Meer RK, Breed MD, Espelie KE and Winston ML (eds) Pheromone communication in social insects Westview Press, Boulder, CO, pp 159-192

Vandermoten S, Mescher MC, Francis F, Haubruge E, Verheggen FJ (2012) Aphid alarm pheromone. An overview of current knowledge on biosynthesis and functions. Insect Biochem Mol Biol 42:155-163. https://doi.org/10.1016/j.ibmb.2011.11.008

Veith M, Lorenz M, Boland W, Simon H, Dettner K (1994) Biosynthesis of iridoid monoterpenes in insects: defensive secretions from larvae of leaf beetles (Coleoptera: Chrysomelidae). Tetrahedron 50:6859-6874

Völkl W, Hübner G, Dettner K (1994) Interactions between Alloxysta brevis (Hymenoptera, Cynipoidea, Alloxystidae) and honeydewcollecting ants: how an aphid hyperparasitoid overcomes ant aggression by chemical defense. J Chem Ecol 20:2901-2915. https://doi.org/10.1007/BF02098397
Wachi N, Nomano FY, Mitsui H, Kasuya N, Kimura MT (2015) Taxonomy and evolution of putative thelytokous species of Leptopilina (Hymenoptera: Figitidae) from Japan, with description of two new species. Entomol Sci 18:41-54. https://doi.org/10.1111/ens.12089

Weiss I, Rössler T, Hofferberth J, Brummer M, Ruther J, Stökl J (2013) A nonspecific defensive compound evolves into a competitionavoidance cue and a female sex-pheromone. Nat Commun 4:2767. https://doi.org/10.1038/ncomms3767

Weiss I, Hofferberth J, Ruther J, Stökl J (2015a) Varying importance of cuticular hydrocarbons and iridoids in the species-specific mate recognition pheromones of three closely related Leptopilina species. Front Ecol Evol 3:19. https://doi.org/10.3389/ fevo.2015.00019

Weiss I, Ruther J, Stökl J (2015b) Species specificity of the putative male antennal aphrodisiac pheromone in Leptopilina heterotoma, Leptopilina boulardi, and Leptopilina victoriae. BioMed Res Int 2015:202965. https://doi.org/10.1155/2015/202965

Wheeler JW, Olagbemiro T, Nash A, Blum MS (1977) Actinidine from the defensive secretions of dolichoderine ants. J Chem Ecol 3:241-244. https://doi.org/10.1007/BF00988439

Wilson EO, Pavan M (1959) Glandular sources and specificity of some chemical releasers of social behavior in dolichoderine ant. Psyche 66:305-308. https://doi.org/10.1155/1959/45675

Wyatt TD (2010) Pheromones and signature mixtures: defining specieswide signals and variable cues for identity in both invertebrates and vertebrates. J Comp Physiol A 196:685-700. https://doi. org/10.1007/s00359-010-0564-y

Wyatt TD (2014) Pheromones and animal behavior. Cambridge University Press, Cambridge

Zimmermann N, Hilgraf R, Lehmann L, Ibarra D, Francke W (2012) Stereoselective synthesis of trans-fused iridoid lactones and their identification in the parasitoid wasp Alloxysta victrix, Part I: dihydronepetalactones. Beilstein J Org Chem 8:1246-1255. https:// doi.org/10.3762/bjoc.8.140 